\title{
Weer eens: Eksegetiese Metodes ${ }^{1}$
}

W S Prinsloo

Abstract

Once again: Exegetical methods

This article is the result of conversations with leading Old Testament scholars in The Netherlands and in Germany. These conversations once again emphasise that there is not one single prevailing exegetical method which is followed in general. Although certain "schools", in which a spectfic exegetical model dominates, can be identified, enough scope for the practise of other methods is offered. Most exegetes are of the opinion that both synchronic and diachronic aspects can be combined in one exegetical model.

Inleidend

Vir die beoefening van die Ou-Testamentiese wetenskap in Suid-Afrika is daar veral twee sake wat altyd aktueel sal en moet bly, naamlik internasionale kontak en die debat rondom eksegetiese metodes. Hier ter lande het die debat oor eksegetiese metodes veral sedert die sewentiger jare posgevat en die debat word steeds voortgesit $^{2}$. In die beginjare van dié debat het die gedagte sterk geloop dat daar net een regte metode is en dat eksegese op gekontroleerde wyse gedoen moet word ${ }^{3}$.

Die vraag kan gevra word of ons geïsoleerde posisie in Suid-Afrika nie indirek daartoe bygedra het nie dat ons op apologetiese wyse angsvallig wou seker maak dat ons alles reg doen. Die afgelope twintig jaar het die Ou-Testamentiese wetenskap in Suid-Afrika egter met rasse skrede vooruitgegaan. Die vordering het veral tot uiting gekom in die hoeveelheid en kwaliteit van publikasies wat gelewer is. Daar het ook 'n groter realisme gekom ten opsigte van metodologie. Die gedagte dat slegs een metode reg is en alle ander metodes verkeerd, het plek gemaak vir die standpunt dat daar ruimte gelaat moet word vir meer as een metode. Die legitimiteit van meer as een metode word erken. Daar is dus meer begrip vir 'n verskeidenheid van metodes. Hoewel daar oor die epistemologie besin en oor die bepalende invloed van die eksegeet se vooronderstelling gedebatteer word, heers daar tog 'n veel groter toleransie ten opsigte van eksegetiese metodes as voorheen. Die huidige klem op 'n lesersgeoriënteerde benadering kan egter die skaal in so 'n rigting laat swaai dat elkeen kan maak wat hy wil sonder dat daar enige kontrole is. Dit sou natuurlik ook 'n oorreaksie wees.

Die debat oor die metodologie van eksegese mag nooit laat vaar word nie. Vir die afgelope meer as 'n dekade het ek ook probeer om op verskeie maniere aan die debat deel te neem ${ }^{4}$ en om kontak met buitelandse eksegete uit te bou. Hierdie artikel reflekteer dan ook gesprekke wat gedurende die Europese somer van 1992 met 'n aantal leidende eksegete in Duitsland en Holland gevoer is. In dié gesprekke is op die metodiek van eksegese gekonsentreer, veral wat die psalms betref. In hierdie artikel word geen beoordeling van die betrokke eksegete gemaak nie, maar die eksegeet word so getrou as moontlik aan die woord gestel. 
2.1 Professor H Irsigler (Bamberg, Duitsland) is een van die bekendste Richterleerlinge 5 . Irsigler promoveer op die boek Sefanja ${ }^{6}$ en skryf sy Habilitationsschrift oor Psalm 737. Sy inleiding op die Hebreeuse grammatika, wat twee bande beslaan ${ }^{8}$, is ook 'n belangrike publikasie en hy het pas opgetree as redakteur van die Richter Festschrift. Hy is 'n tipiese Richterschüler in die sin dat hy literaturwissenschaftlich werk, die eksegetiese "stappe" van Richter getrou navolg en dus ook polemiseer teen die histories-kritiese metode. Tog is Irsigler van mening dat hy die Richtermetode verder ontwikkel het en kritiek wat soms teen dié metode uitgespreek word, ondervang deur nie so streng tussen Ausdruck $(=$ Form) en Inhalt te onderskei nie. Hy gee by elke eksegetiese "stap" aan beide dié fasette aandag. 'n Teks kan alleen verstaan word, sê Irsigler, as al die teks-Verhältnisse op alle vlakke blootgele word. Vir Irsigler is dit baie belangrik dat die individualiteit van elke teks eers ondersoek moet word. Daarna moet die geykte/tipiese faset (Gattungsaspek) ondersoek word. Soos Richter, wil hy ook Nachprufbar werk. Hoewel elke eksegeet 'n vooronderstelling het, moet dié Vorverständnis geminimaliseer word en moet die eksegeet daarvan bewus gemaak word. Die eksegeet moet dus nie hipoteties met die teks omgaan nie, maar met die teks as kontrolemiddel. Daar moet dus so veel as moontlik met die teks omgegaan word en die teks moet so gedetailleerd as moontlik analiseer word. Irsigler se kritiek teen die histories-kritiese metode is dat dié metode te spekulatief is. Hy het dit ook teen byvoorbeeld die psigologiese en feministiese lees van tekste omdat dié benaderings te veel goed van buite af in die teks inlees. Irsigler vra ook historiese vrae aan die teks, maar dan doen hy dit aan die hand van sy teksanalise. Hy beklemtoon dit dat historiese sake vir hom ook belangrik is en dat sowel sinkroniese as diakroniese vrae aan dieselfde teks gevra kan word - maar dan in die regte volgorde, naamlik eers sinkronies en dan diakronies. Hy is van oordeel dat sy metode op sowel poëtiese as prosatekste toegepas kan word. Die metode moet egter by die teks aanpas en nie andersom nie. Op die vraag of hy 'n spesifieke teoretiese onderbou het, sê hy dat hy byvoorbeeld by Greimas en die Praagse skool aansluit. Hy leen met ander woorde op verskillende plekke, maar hy verwys tog telkens terug na Richter se boek as sy eintlike vertrekpunt.

2.2 Professor G Wanke (Erlangen, Duitsland), 'n Oostenryker van geboorte en student en opvolger van die beroemde Fohrer, is aangewys in die plek van Otto Kaiser as redakteur van die belangrike Ou-Testamentiese tydskrif Zeitschrift für die alttestamentliche Wissenschaft. In sy proefskrif wat gehandel het oor die Sionsteologie ${ }^{9}$ werk Wanke nog op 'n histories-kritiese wyse. In 'n publiklasie oor die metodologie van eksegese waarvan Fohrer die redakteur is en waarin Wanke een van die belangrikste medewerkers is, lyk dit egter of Wanke in 'n literatuurwetenskaplike rigting neig 10 . Hy is van mening dat die histories-kritiese metode en die literatuurwetenskaplike metode in een eksegetiese model gekombineer kan word: Die Bybel bestaan uit literatuur, maar dié literatuur kan nie los van 'n historiese konteks gesien word nie. In die boek Exegese des Alten Testaments word gepoog om hierdie twee fasette met mekaar te versoen. Die boek is duidelik deur die Richtermetode beînvloed, maar Wanke is van opvatting dat die eksegetiese stappe nie so rigied - soos by die Richterskool - toegepas behoort te word nie. Die 
skerp skeiding tussen Form en Inhalt kan ook nie gehandhaaf word nie. Wanke verkies egter om eerder van Struktur as van Form te praat omdat laasgenoemde term 'n te gelade betekenis in die Gunkeliaanse sin van die woord het. Volgens Wanke is 'n eksegetiese metode 'n manier om agter te kom wat in die teks staan. 'n Teks het betekenis en betekenis word nie deur'n eksegeet aan 'n teks toegeken nie. As 'n teks nie betekenis gehad het nie, sou dit nie die moeite werd gewees het om eksegeet te wees nie. 'n Teks bestaan uit verskillende taalelemente en deur 'n bestudering van dié elemente word betekenis blootgelê. Hoewel elke eksegeet 'n Vonverständnis het, moet hy dié vooronderstelling deur die teks laat verander. Eksegese is dus 'n dialoog tussen die teks en die eksegeet. Wanke het nie veel erg aan die psigologiese/sosiologiese lees van 'n teks of die resepsieteorieë nie. Die eksegetiese proses behoort op ' $n$ intersubjektiewe vlak - in die sin dat die eksegeet sy metode teenoor ander eksegete kan verantwoord - Nachprufbar te wees. Vir 'n eksegeet is dit waardevol om van die Wirkungsgeschichte van 'n teks kennis te neem, maar dit mag nooit die kriterium word waarvolgens die teks geïnterpreteer moet word nie.

2.3 Professor C Houtman (Kampen, Nederland) is die opvolger van E Noort (J L Koole het die leerstoel voor Noort beklee). Houtman het by Nic H Ridderbos aan die Vrije Universiteit (Amsterdam) gepromoveer en is die hoofredakteur van 'n nuwe Ou-Testamentiese kommentaarreeks, Historical Commentary on the Old Testament, wat in die vooruitsig gestel word. Hy konsentreer veral op die Pentateug11. Sy aanpak is literêr-krities. Hy begin met die Endgestalt van die teks en werk dan terug. Sy bedoeling met die literêre kritiek is om die wordingsproses van die teks te rekonstrueer om sodoende ook die ontwikkelingsgang van die godsdiens van Israel te bepaal. Vir Houtman is dit belangrik om die historiese konteks van 'n teks - nie die oerkonteks waarna die teks sou verwys nie, maar die konteks waarvoor 'n teks geskryf is - te bepaal. Hy erken egter dat dit'n "spekulatiewe besigheid" is. Oor die verhouding sinkronie/diakronie sê hy dat $\mathrm{E}$ Talstra die twee fasette probeer kombineer het in sy proefskrif ${ }^{12}$, maar dat hy nie regtig daarin geslaag het nie. Houtman wek die indruk asof hy self ook nie daarin belangstel om die twee fasette met mekaar te kombineer nie omdat hy meer diakronies werk. Hy is skepties teenoor 'n struktuuranalitiese metode waarin daar 'n eenheid in die teks gesoek word waar daar nie werklik eenheid bestaan nie. Houtman glo basies aan 'n oop kanon in die sin dat die herinterpretasieproses wat reeds in die Ou Testament self ' $n$ aanvang neem, na die afsluiting van die kanon voortgesit word. Die Ou Testament is die produk van 'n lang oorleweringsproses van verskillende tradisies wat oor en oor geaktualiseer is in die loop van Israel se geskiedenis. Volgens Houtman speel die vooronderstelling van 'n eksegeet 'n belangrike rol, maar nogtans moet die ideaal tot objektiwiteit nooit laat vaar word nie.

2.4 Professor F-L Hossfeld (Bonn, Duitsland) is 'n Katoliek en 'n student van die bekende E Zenger. Hy het al wyd gepubliseer: oor die Pentateug13, oor die boek Esegiël14 en ook oor die psalms ${ }^{15}$. Hy begin met die Endgestalt van die teks en hy is sekerlik ook deur die Richtermetode beïnvloed. Die teks moet so volledig moontlik geanaliseer word en die individualiteit van elke teks moet eerbiedig word. Hoewel hy nie 'n strakke volgorde van eksegetiese stappe voorstaan nie, handhaaf 
hy, veral wat die psalms betref, meestal die volgende eksegetiese stappe: Hy begin met 'n sintakties-stilistiese analise; daarna 'n semantiese analise waarin hy reeds aandag aan diakroniese vergelykings gee. Vervolgens kyk hy na die pragmatische Bestimmung of Sprechintention van die onderlinge dele van 'n psalm. Laastens spreek hy hom oor die groeiproses van die psalm uit. Hy identifiseer byvoorbeeld 'n kern, en indien sy analise dit sou aantoon, ook dele wat later tot die psalm bygevoeg sou gewees het. ' $n$ Teksimmanente benadering - of soos wat hy verkies om dit te noem, ' $n$ literatuur-wetenskaplike benadering - kan ook Spannungen in die teks aan die lig laat tree. Die spanninge moet nie wegredeneer word nie, maar moet verklaar word. Hy ervaar dus nie 'n botsing tussen die teksimmanente en die historiese benaderings nie. Hy keer egter elke keer weer na die Endgestalt toe terug en dink nie dat die sogenaamde Originaltext belangriker as die finale teks is nie. Teen 'n oorbeklemtoning van die Endgestalt, soos byvoorbeeld by Rendtorff en Childs, moet daar egter ook gewaak word. Hy het ook nie veel simpatie met 'n strukturalistiese benadering soos dié wat Auffret op die psalms toepas nie. Hy wil, soos reeds aangetoon, 'n kombinasie van die literatuurwetenskaplike en historieskritiese metodes daar stel. Die klem val by hom egter beslis op die literatuurwetenskaplike aspekte van die eksegetiese proses. Wat die psalms betref, probeer hy egter ook om, indien moontlik, die historiese of kultiese konteks van 'n psalm te rekonstrueer. Iets soos die לרוֹ ("vir Dawid") opskrifte by die psalms beskou hy egter nie as kronologies/historiese aanduidings nie, maar eerder as teologiese aanduidings. By die psalms moet daar, wat die Endgestalt betref, volgens Hossfeld ook gevra word na die verhouding van individuele psalms se verhouding tot mekaar. Daar moet ook gekyk word na die groeperings en groter indelings in die psalmboek. Hossfeld is van oortuiging dat die psalms op 'n doelbewuste manier langs mekaar geplaas en gerangskik is. Soos wat die kanoniese vorm (Endgestalt) van die psalmboek ernstig opgeneem behoort te word, so ook die kanoniese vorm van die Ou Testament as geheel.

2.5 Professor E Haag (Trier, Duitsland), 'n Katolieke geleerde het ook al wyd gepubliseer: oor die boek Daniël16, oor Deuterojesaja ${ }^{17}$, oor die monoteisme in die Ou Testament ${ }^{18}$ en ook oor die psalms ${ }^{19}$. Hoewel hy nie 'n starre volgorde van eksegetiese stappe handhaaf nie, volg hy tog, veral wat die psalms betref, breedweg die volgende volgorde: Eerstens gee hy aandag aan literarkritische vrae. Hy gebruik die term Literarkritik eerder soos wat Steck ${ }^{20}$ dit gebruik en nie soos Richter ${ }^{21}$ nie. Hier word veral oor die Einheitlichkeit van die teks gehandel. Die vraag na latere redaksionele byvoeginge sou ook hier bespreek kon word. In sommige gevalle, soos by Psalm 1, blyk daar geen latere redaksionele byvoegings te wees nie. In ander gevalle sou daar egter reeds op hierdie stadium, volgens Haag, Zusätze aangetoon kon word. Dié byvoegings is egter nie onbelangrik nie, maar het net soveel gewig as die "oorspronklike" teks. Vervolgens stel Haag die Struktur en die Form aan die orde. Onder eersgenoemde rubriek gee hy aan sintaktiese en stilistiese sake aandag. Hier maak hy veral van die metode van Richter gebruik. By Form gee hy veral aandag aan die Gattung en die funksie daarvan. Onder hierdie hoof gee hy ook aandag aan die Sitz im Leben van die teks, want Haag sien die Bybel nie net as literatuur nie, maar as die produk van 'n geloofsgemeenskap. Die groei van die teks en die gemeenskap waaruit die teks gegroei het, is baie belangrik vir hom. Haag werk basies histories van aard en is krities teenoor die metodes van byvoorbeeld 
Rendtorff en Richter omdat dit volgens hom eensydig is. Vervolgens gee hy aan die tradisiekritiek aandag. Hieronder gee hy ook aan semantiese sake aandag. Laastens val die fokus op die redaksiekritiek. Haag beklemtoon dit egter dat wanneer hy konkreet met eksegese besig is, hy nie die verskillende stappe geisoleerd of in 'n vaste volgorde toepas nie. Hy pas as't ware die hele eksegetiese proses geintegreerd op die teks toe. Dit is eers wanneer hy die resultaat van sy eksegese neerpen dat hy dit in 'n sekere volgorde weergee. Haag sien geen probleem daarin om diakroniese en sinkroniese elemente in dieselfde eksegetiese proses te kombineer nie.

Hierdie oorsig demonstreer dat daar geen eenstemmigheid onder eksegete is oor die eksegetiese metode wat gevolg moet word nie. Ruimte word gebied aan elkeen om dié metode te volg wat by sy tradisie en belangstelling pas. 'n Mens kry ook die indruk dat daar nie eintlik veel gedebatteer word oor die vraag of 'n metode reg of verkeerd is nie en dat die klem eerder daarop val dat daar eksegese gedoen moet word.

Dat daar besliste "skole" geïdentifiseer kan word waarin 'n sekere eksegetiese benadering domineer, is ook kenmerkend van die Europese situasie. So is daar beslis nog 'n sterk histories-kritiese benadering by baie eksegete terug te vind. Dit kan egter ook nie ontken word nie dat die literatuurwetenskaplike benadering met sy klem op die analise van die finale teks, veral onder die invloed van Richter, baie veld gewen het. Meeste eksegete beleef die verhouding sinkronie/diakronie nie as 'n of/of verhouding nie, maar is oortuig daarvan dat hierdie twee fasette komplementerend tot mekaar in een eksegetiese model gekombineer kan word.

\section{NOTAS:}

1 Hierdie artikel word opgedra aan my vriend en kollega, prof J H le Roux, saam met wie ek bevoorreg was om die akademiese reis waaruit hierdie artikel gespruit het, mee te maak.

2 Vir een van die mees resente bydraes in dié verband, vergelyk L C Jonker, "Eksegese sonder grense? Gedagtes rondom meerdimensionele Skrifuitleg", Ned Geref Teologiese Tydskrif 32/4 (1991), 552-560.

3 Die artikel van J A Loader ("Gedagtes oor gekontroleerde eksegese", HTS 34 [1978], 1-11) het 'n groot invloed in dié verband uitgeoefen.

4 Vergelyk byvoorbeeld W S Prinsloo, "Die metodiek van eksegese: 'n Diskussie", Ned Geref Teologiese Tydskrif 20/3 (1979), 201-210; W S Prinsloo, "Oor eksegetiese metodes en nog wat: 'n Gesprek", HTS 46 (1990), 144-152; W S Prinsloo, "Perspektiewe op die stand van die Ou-Testamentiese wetenskap in Groot Brittanje", Skrif en Kerk 13/1 (1992), 55-64.

5 Die eksegetiese metode van W Richter en veral sy boek Exegese als Literaturwissenschaft. Entwurf einer alttestamentliche Literaturtheoric und 
Methodologie, Göttingen 1971, het nie alleen in Duitsland nie, maar ook hier in Suid-Afrika groot invloed uitgeoefen. Die Richterskool het vandag nog groot invloed deurdat Richterleerlinge soos Seidl, Irsigler, Gross en Schweizer prominente leerstoele in Duitsland beklee.

6 H Irsigler, Gottesgericht und Jahwetag. Die Komposition Zef 1,1-2,3, untersucht auf der Grundlage der Literarkritik des Zefanjabuches, St Ottilien 1977.

7 H Irsigler, Psalm 73 - Monolog eines Weisen. Text, Programm, Struktur, St Ottilien 1984.

8 H Irsigler, Einführung in das Biblische Hebräisch.J. Ausgewählte Abschnitte der althebräische Grammatik, St Ottilien 1981; Einführung in das Biblische Hebräisch.II. Übungen, Texte Paradigmen, St Ottilien 1979.

9 G Wanke, Die Zionstheologie der Korachiten in ihrem traditionsgeschichtlichen Zusammenhang (BZAW 97), Berlin 1966. Hy publiseer ook 'n belangwekkende boek oor Jeremia, naamlik Untersuchungen zur sogenannten Baruchschrift (BZAW 122), Berlin 1971.

10 G Fohrer e a, Exegese des Alten Testaments. Einführung in die Methodik, Heidelberg 21976. Wanke is verantwoordelik vir drie hoofstukke in die boek waaronder die belangrike deel wat handel oor sprachliche Analyse.

11 Vergelyk sy Inleiding in de Pentateuch, Kampen 1980. Hy publiseer ook 'n kommentaar op Eksodus: Exodus I (Exodus 1:1-7:13), (COT), Kampen 1986 en Exodus II (Exodus 7:14-19:25), (COT), Kampen 1989.

12 Vergelyk E Talstra, Het gebed van Salomo: Synchronie en diachronie in de kompositie van I Kon 8:14-61, Amsterdam 1987.

13 F-L Hossfeld, Der Dekalog: Seine späten Fassungen, die originale Komposition und seine Vorstufen, Göttingen 1982; F-L Hossfeld, "Zum synoptischen Vergleich der Dekalogfassungen: Eine Fortführung des begonnenen Gesprächs", in F-L Hossfeld (Hrsg), Von Sinai zum Horeb. Stationen alttestamentlicher Glaubensgeschichte. Festschrift E Zenger, Würzburg 1989, 73-117.

14 F-L Hossfeld, Untersuchungen zu Komposition und Theologie des Ezechielbuches, Würzburg 1977; F-L Hossfeld, "Die Tempelvision Ez 8-11 im Licht unterschiedlicher methodischer Zugänge", in: J Lust (ed), Ezekiel and his book, Leuven 1986, 151-165; F-L Hossfeld, "Probleme einer ganzheitlichen Lektüre der Schrift - dargestellt am Beispiel Ez 9-10", ThQ 167 (1987), 266-277.

15 Vergelyk byvoorbeeld F-L Hossfeld, "Der Wandel des Beters in Ps 18. Wachtumsphasen eines Dankliedes", in: E Haag \& F-L Hossfeld (Hrsg), Freude an der Weisung des Herm. Beiträge zur Theologie der Psalmen. Festgabe zum 70.Geburtstag von Heinrich Groß (SBS 13), Stuttgart 1986, 171-190; F-L Hossfeld, "Nachlese zu neueren Studien der Einzugsliturgie von Ps 15", in: J 
Zmijewski (Hrsg), Die alttestamentliche Botschaft als Wegweisung. Festschrift für Heinz Reinelt, Stuttgart 1990, 135-156.

16 E Haag, Die Erretung Daniels aus der Löwengrube: Untersuchung zum Ursprung biblischen Danieltradition (SBS 110), Stuttgart 1983; E Haag, "Die drei Männer im Feuer nach Dan 3, 1-30", TrThZ 96 (1987), 21-50.

17 Vergelyk byvoorbeeld E Haag, "Das Opfer des Gottesknechts (Jes 53,10)", $\operatorname{TrThZ} 86$ (1977), 81-98; E Haag, "Bund des Volkes, Licht der Heiden (Jes 42,6)", in: J Blank \& G Hasenhüttl (Hrsg), Glaube an Jesus Christus, Düsseldorf 1980, 28-41; E Haag, "Die Botschaft vom Gottesknecht. Ein Weg zur Überwindung der Gewalt", in: N Lohfink (Hrsg), Gewalt und Gewaltosigkeit im Alten Testament, Freiburg im B 1983, 159-213.

18 E Haag (Hg), Gott, der einzige: Zur Entstehung des Monotheismus im Alten Testament, Freiburg 1985.

19 Vergelyk byvoorbeeld E Haag, "Psalm 88", in: E Haag \& F-L Hossfeld (Hrsg), Freude an der Weisung des Herm. Beiträge zur Theologie der Psalmen. Festgabe zum 70.Geburtstag von Heinrich Groß (SBS 13), Stuttgart 1986, 149170; E Haag, "Psalm 1. Lebensgestaltung nach dem alttestamentlichen Menschenbild", in: R Mosis \& L Ruppert (Hrsg), Der Weg zum Menschen Zur philosophischen und theologischen Anthropologie. Für Alfons Deissler, Freiburg 1989, 153-172; E Haag, "Zion und Schilo. Traditionsgeschichtliche Parallelen in Jeremia 7 und Psalm 78", in: J Zmijewski (Hrsg), Die Alttestamentliche Botschaft als Wegweisung. Festschrift für Heinz Reinelt, Stuttgart 1990, 85-117.

20 Vergelyk H Barth \& O H Steck, Exegese des Alten Testaments. Leiffaden der Methodik, Neukirchen-Vluyn ${ }^{7} 1977,34$.

21 Vergelyk Richter, $a$ w, 50-69. 